\title{
Micros, pequeñas y grandes empresas, dos circuitos económicos separados. Lázaro Cárdenas, Michoacán
}

\author{
Micro, small and large business, \\ two separate economic circuits. \\ Lazaro Cardenas, Michoacan
}

Jorge Martínez-Aparicio*

\begin{abstract}
Ciudad Lazaro Cardenas, Michoacan, is characterized by the formation of two circuits that operate and reproduce separately and discontinuously. In urban areas, on the one hand, large establishments located in the port area are linked to world trade. Moreover, a large aggregate of micro and small companies is scattered and attached to the consumption fund of the working population. Despite regional development policies and heavy investments implemented in the area since the seventies, productive links between the two circuits have not been built. Thus, both acquire their major inputs from outside the region. The micro and small enterprises appear as a minor player among the priorities for investment promotion of federal and state government, whilst large companies are considered strategic for its links to international trade.
\end{abstract}

Keywords: Ciudad Lazaro Cardenas, small and large companies, international enclave.

\section{Resumen}

Ciudad Lázaro Cárdenas, Michoacán, se caracteriza por la constitución de dos circuitos socioeconómicos que operan y se reproducen de manera separada y desarticulada. En el ámbito urbano, por un lado, los grandes establecimientos localizados en el recinto portuario están eslabonados con el comercio mundial. Por otra parte, un numeroso agregado de micros y pequeńas empresas está disperso y acoplado al fondo de consumo de la población asalariada. A pesar de las políticas de desarrollo regional y las elevadas inversiones aplicadas en la zona desde los años setenta, no se han construido enlaces productivos entre los dos circuitos. Por tanto, ambos adquieren sus principales insumos fuera de la región. Las micro y pequeñas empresas aparecen como un sector secundario entre las prioridades de fomento de inversión de los gobiernos federal y estatal; entre tanto las grandes empresas se consideran estratégicas por su vinculación con el comercio internacional.

Palabras clave: Ciudad Lázaro Cárdenas, pequeñas y grandes empresas, enclave internacional.

\footnotetext{
*Universidad Michoacana de San Nicolás de Hidalgo, México. Correo-e: maparic@umich.mx.
} 


\section{Introducción $^{1}$}

La pequeña y mediana empresa en Lázaro Cárdenas, Michoacán, aparece como un sector económico secundario entre las prioridades de fomento de inversión de los gobiernos federal y estatal en la zona. Son las grandes empresas establecidas en el puerto las que se consideran de mayor dinamismo y estratégicas por su vinculación con el comercio internacional. De hecho, en la política económica estatal, orientada a la región de la costa michoacana, se acentúa la importancia y el papel de las grandes inversiones.

El alcance y la actuación de las empresas pequeñas y de mediano tamańo en el área aparecen al margen de las grandes, e involucradas en actividades comerciales y de servicio para la amplia masa de trabajadores en el puerto. La derrama salarial a través de las grandes es la principal fuente de las pequeñas y medianas empresas de la ciudad.

La paradoja no es que en la zona las empresas grandes tengan mayor presencia que las pequeñas, sino que entre ellas no existan vínculos económicos que alimenten las posibilidades de difundir el crecimiento a partir de las empresas motrices. Entre las micro, pequeñas y grandes empresas establecidas en Ciudad Lázaro Cárdenas no existen enlaces entre ellas. Más aún, existen áreas económicas que operan de modo separado, cada una con su propio mercado; mientras que el único elemento articulador es la fuerza de trabajo de la región, ya sea como asalariado o como consumidor.

Se establecen así, en la zona, dos circuitos económicos. Por un lado, el de los grandes establecimientos localizados en el recinto portuario, eslabonados con el comercio mundial y la internacionalización del capital. Por otro, un numeroso agregado de micro y pequeñas empresas (Mipymes) disperso en la zona urbana y acoplado al fondo de consumo de la diversa población asalariada. No existen enlaces productivos entre los dos circuitos, ambos adquieren sus principales insumos fuera de la región.

Así, cada circuito económico se circunscribe en un área de la ciudad, cada conjunto de las empresas, micro, pequeńas y grandes se pueden identificar en Ciudad Lázaro Cárdenas por su localización específica.

Por un lado, al interior del complejo portuario se establece el conjunto de las grandes empresas corporativas ligadas al mercado nacional y exterior. En general es el área reservada sobre todo para la promoción de negocios y atracción de inversión foránea. La preocupación del gobierno

\footnotetext{
${ }^{1}$ Este trabajo corresponde al proyecto de investigación “Territorio y enclave en Lázaro Cárdenas, Michoacán”, aprobado en el Programa 2008 de la Coordinación de Investigación Científica de la UMSNH.
} 
estatal es construir infraestructura competitiva para la expansión de capital en la zona y bajo la lógica del comercio internacional.

En el área externa al recinto portuario, en la zona urbana se desperdigan, en conglomerados, numerosos negocios micro y pequeńos, muchos informales, que se ligan a la actividad comercial del consumo de los habitantes de la ciudad, que se alimentan de la derrama salarial generada por las empresas establecidas al interior del puerto. Son negocios para el comercio y de servicios que no están articulados a las empresas del recinto portuario e industrial.

En la ciudad, las Mipymes aparecen fuertemente vinculadas con los requerimientos de consumo comercial y de servicios del conjunto asalariado, importante por el monto global del ingreso gastado, a través de la actividad de las grandes empresas. Más allá del área urbana, la población rural se desplaza y moderniza bajo la lógica de la ciudad.

El presente trabajo busca describir la composición de cada uno de los circuitos y áreas socioeconómicas constituidas en torno a los distintos tipos de empresas establecidas en Ciudad Lázaro Cárdenas, como espacios separados que limitan las posibilidades del desarrollo regional.

El análisis parte del supuesto de considerar la necesidad de la integración y articulación entre las distintas empresas establecidas en un lugar, a modo de un sistema productivo y en la búsqueda del desarrollo regional, como postulado que se reivindica en las políticas económicas y de desarrollo, aplicadas en particular para la costa michoacana por los gobiernos de la entidad.

Como sustento de esas expectativas para el desarrollo y en función de la situación socioeconómica constituida en la zona, se revisa el papel que supone el predominio de las grandes empresas en un área socioeconómica específica y su relación con el entorno en la difusión del crecimiento y en el establecimiento de más y nuevas empresas, en este caso con respecto a las micro y pequeñas, como condición del desarrollo regional.

Con base en esa referencia, se revisan y analizan las políticas públicas de los gobiernos michoacanos instrumentadas en la región costa, en particular para Lázaro Cárdenas y que, a final de cuentas, aparecen sólo circunscritas al área de Ciudad Lázaro Cárdenas, la cabecera municipal, además de restrictivas en términos de un desarrollo local.

En particular se analizan las propuestas programáticas orientadas al conjunto de empresas establecidas en Ciudad Lázaro Cárdenas, a fin de caracterizar, por un lado, la correspondencia entre las políticas públicas y los proyectos de inversión de los corporativos instalados en el puerto; y por otro, la ausencia de programas específicos, con envergadura similar, para el sector de las micro y pequeñas empresas y que estuvieran engarzados a las trayectorias de las grandes empresas. 
Más allá del relativo contraste entre los supuestos en que se fincan las políticas regionales y la situación socioeconómica existente en la zona, el presente documento destaca el carácter accesorio y secundario de los pequeños negocios dedicados al comercio y los servicios. Asimismo, la relativa desarticulación con respecto al complejo industrial portuario, la distinción de los circuitos socioeconómicos en que operan cada uno de los dos principales conglomerados de empresas, y la separación de los espacios contiguos, que albergan condiciones y expectativas diferentes de desarrollo.

\section{Desarrollo regional, entre grandes y pequeñas}

Las pequeñas empresas como referentes centrales del desarrollo regional tomaron importancia a partir de los años ochenta, en el marco de la crisis iniciada en los setenta y como efecto de la flexibilidad del mercado y la automatización implantada a través de los procesos de innovación productiva.

Entre las pequeñas empresas se identifican diversas ventajas: la capacidad de generación de empleos cuando absorben una parte importante de la población económica, y la asimilación y adaptación de tecnología. Contribuyen al desarrollo regional por su arraigo en el lugar y su presencia local en diversas regiones. Responden con flexibilidad al tamaño del mercado y tienen rápida resolución de problemas, por el reducido número de personal y el mayor conocimiento de los empleados. Implican un sencilla planeación y organización. No requieren elevados montos de capital y mantienen una unidad de mando, lo que permite mayor vinculación entre las funciones administrativas y de operación. Pueden funcionar con precios competitivos en cuanto que los gastos no son elevados y las ganancias no son excesivas.

No obstante la importancia de la pequeña empresa, las grandes continúan ocupando un lugar preponderante en la actividad económica regional. En el contexto de los años noventa, cuando el problema del desarrollo se estructura con base en la expectativa de lo local y endógeno, en el entorno de reestructuración, crisis prolongada y de internacionalización del capital, el papel de la gran empresa y su convergencia con los requerimientos territoriales de un lugar en particular, se convierten, otra vez, en un referente analítico.

En los últimos años se ha asumido que la política de polos de desarrollo puede aplicarse en el contexto del desarrollo local, en cuanto que las grandes empresas pueden adecuarse a las formas de organización flexible y estimular la integración de unidades externas a los sistemas productivos de un lugar en particular. Se supone la convergencia entre las es- 
trategias de la gran empresa y el territorio y su confluencia con efectos positivos para provocar el desarrollo. La gran empresa transnacional se considera un agente capaz de converger con las estrategias territoriales de un área en concreto (Vázquez, 1997).

No obstante, en áreas periféricas la experiencia señala que dominan los efectos negativos esperados territorialmente en el área en que se instala la gran empresa. Más que una convergencia aparece la divergencia y la desarticulación entre la inversión de las grandes empresas instaladas en un lugar y el desarrollo de la localidad. En esa medida, la acción de la gran empresa en un entorno de periferia no siempre genera desarrollo regional, no converge con las estrategias territoriales. Puede provocar formas de enclave, que en el contexto actual se expresa en la forma de enclave internacional (Martínez, 2006).

Un lugar fundamental en la propagación del crecimiento regional lo jugarían las grandes empresas con capacidad innovadora, que pueden ejercer una amplia influencia y dominio en otras entidades económicas. Se trata de empresas dinámicas que por su gran tamańo, crecimiento acelerado, capacidad de innovar y generar impulsos externos pueden provocar enlaces interindustriales con empresas de menor tamaño.

La interdependencia entre las industrias en función de sus enlaces, de acuerdo con la sistematización que hizo Hermansen sobre las diversas formulaciones de Perroux, implica la posibilidad de generar efectos de difusión productiva hacia atrás y hacia adelante. En cualquiera de los casos, es una fuerza de expansión o estancamiento en razón de la aptitud innovadora de la empresa líder.

Los enlaces hacia atrás estarían dados por el dominio de una industria con respecto a otras empresas proveedoras de insumos o productos intermedios: "Según Perroux, puede afirmarse que tal industria dominante por enlace hacia atrás es una industria fundamental en la medida en que determine la magnitud de la expansión inducida en las industrias dependientes en relación con su propia expansión" (Hermansen, 1977: 34).

En los enlaces hacia adelante significa ocupar una posición de empresa dominada, como fabricante de productos intermedios para la demanda final y que depende de otras entidades para su crecimiento. No obstante, podría inducir la expansión hacia adelante mediante la transmisión de sus innovaciones.

Cabe también la posibilidad de industrias que pueden generar impulsos de crecimiento mediante enlaces simultáneos hacia atrás y hacia adelante. Serían unidades con una fuerte capacidad de propulsión del crecimiento económico e innovación tecnológica.

La consecuencia final implica estructurar núcleos industriales dinámicos para generar y difundir innovaciones, que estimularían el estableci- 
miento de nuevas empresas a través de relaciones de interdependencia como un principio para impulsar el crecimiento del conjunto económico $y$, en esa medida, la posibilidad del desarrollo.

El ordenamiento interindustrial puede también formarse por aglomeraciones en torno a un núcleo de industrias con una importante potencia de propulsión y transmisión de impulsos de crecimiento. El complejo industrial, entonces, se constituye por un grupo de industrias motrices, como integrantes del núcleo, son empresas nuevas que operan con elevados niveles tecnológicos, alta demanda y capacidad para generar, adoptar y transmitir innovaciones. El complejo industrial opera como un supermultiplicador por la fuerte influencia y dominio que ejerce en su entorno económico (Hermansen, 1977: 34-35).

Al igual que la Comisión de la Unión Europea, pero sobre todo la Comisión Económica para América Latina y el Caribe (CEPAL) le ha asignado a la gran empresa transnacional un papel principal en el desarrollo. Para América Latina, la Cepal ha reconocido a la inversión extranjera multinacional como un agente que refuerza y estimula el desarrollo; no obstante, sugiere políticas de regulación y vigilancia para que el desarrollo sea ordenado por empresas de la zona y en la búsqueda de una mayor integración de la región.

Desde los ańos cincuenta del siglo xx, aunque la cepal enfatizaba la promoción de fondos públicos para el desarrollo, ya existía el interés por los efectos del gran capital externo. En los sesenta, una vez que se vislumbran las limitaciones del proceso sustitutivo de importaciones, se comenzaron a evaluar los efectos de la inversión externa y la posibilidad de atraerla para promover la exportación manufacturera. En los años setenta, alrededor del análisis de los estilos de desarrollo, el papel de la gran empresa transnacional ocupa un lugar principal, aun cuando se destacan sus limitaciones ante las expectativas del desarrollo en la región. Entre las décadas ochenta y noventa, bajo el principio de transformación productiva con equidad, crece la atención hacia las empresas transnacionales. Particularmente desde los años noventa se asume la apertura de las economías y la necesidad de atraer a la gran empresa por su aporte tecnológico y de capital a la región. Al mismo tiempo, se mantiene la pretensión de que las empresas latinoamericanas deben liderar la estrategia de desarrollo en la región (Kerner, 2003).

En el contexto de los años noventa, siguiendo a Vázquez Barquero (1997), se admite que la acción de la gran empresa, como unidad motriz del desarrollo, tendría la capacidad de generar un proceso de difusión de innovaciones en el lugar en el que se instala, como un polo de desarrollo. Con la capacidad de generar vínculos con un conjunto de empresas pequeñas, se generaría un efecto dinámico y multiplicador para dinamizar 
el sistema productivo local. La gran empresa, como fuerza motriz, tendría la facultad de impulsar un sistema productivo local, compartiendo formas de organización, cultura productiva, tecnologías y objetivos comunes, en esa medida operarían mecanismos difusores de innovación.

La posibilidad de que la gran empresa pueda ocupar un lugar significativo en el desarrollo local, se acredita con el hecho de que en sus procesos de reestructuración esté implicada su adaptación a los procesos y formas de organización flexible, a los cambios del mercado; por lo que se aproximaría a los contextos locales con la posibilidad de lograr economías de escala y compartir costos de transacción. La gran empresa abandonaría estrategias funcionales donde el territorio es identificado sólo como un lugar de localización.

Las nuevas condiciones de la competencia conducen a la gran empresa a adoptar nuevas formas de gestión y dirección, descentralizadas en diferentes regiones. En esa medida, la gran empresa podría instrumentar diferentes estrategias que la vinculen con las empresas e instituciones locales en donde se instala, con una visión de adaptación a los contextos locales. En el lugar se constituirían redes con las plantas subsidiarias, organizadas horizontalmente, con una relativa autonomía e integradas, no obstante, de modo centralizado en la gestión, distribución y comercialización; se establecerían relaciones de colaboración con los proveedores y sus clientes, lo que llevaría a la formación grupos empresariales endógenos.

En esos términos, la reorganización estructurada en torno a la gran empresa, como factor innovador, operaría como un elemento que da prioridad en su inserción a la lógica territorial donde se implanta, fortalece las relaciones con los productores e instituciones locales como objetivos estratégicos de sus operaciones, y se ocuparían por mantener y reproducir el entorno local.

El cambio en las estrategias de las grandes empresas tendría que estar acompañado y orientado, a través de los procesos de reestructuración del capital, por la acción del Estado y mediante las iniciativas locales y regionales, con capacidad para promover el crecimiento y la transformación territorial de manera descentralizada, e inclusive autónoma. Estimular acciones desde el ámbito local y del Estado que provoquen la competitividad de las empresas en el impulso del desarrollo local. Ello implicaría mejorar la infraestructura, la disposición de recursos, la promoción de empresas, de ambiente de innovación y de redes organizativas que fortalezcan la presencia de las instituciones y la acción de la sociedad en el espacio productivo de un lugar.

En consecuencia, la gran empresa innovadora se vería atraída por aquellas localizaciones con recursos, infraestructura y formas de organización, con calidad y capacidad innovadora para generar economías ex- 
ternas de escala y con un marco institucional propicio a la empresa, la competitividad y cooperación.

En esta lógica, la acción de la gran empresa podría considerarse como un agente activo en las estrategias del desarrollo local; sería un elemento catalizador del crecimiento y desarrollo. Ello es posible, aclara y precisa Vázquez Barquero (1997), en tanto que la gran empresa puede establecer sus plantas en áreas cuya dinámica productiva garantiza un desarrollo endógeno, incluso en el contexto de la internacionalización del capital.

Es comprensible que Vázquez Barquero se refiera a las experiencias fincadas en el contexto de la Comunidad Europea; se trata de regiones con capacidad de asimilarse a la dinámica de la expansión del capital en el ámbito mundial, como zonas exitosas que por sí pueden integrarse al proceso extensivo del actual régimen capitalista; serían áreas que por su trayectoria de desarrollo endógeno pueden involucrarse en el proceso de internacionalización del capital y mejorar su posición con estrategias competitivas. En esos términos, en efecto, la gran empresa y las organizaciones locales pueden confluir en el espacio local.

De ese modo, la convergencia entre la gran empresa y el lugar donde se establece es posible en las zonas en que pueden asimilarse, como ganadoras o exitosas, a la lógica actual de la acumulación del capital. En ese margen se puede entender la hipótesis de la convergencia entre los propósitos de competitividad de la gran empresa con el desarrollo endógeno, cuando ambos estimulan la competitividad de la gran empresa y del territorio. La acción de las grandes empresas y las iniciativas locales contribuyen al surgimiento del desarrollo en un sitio.

En consecuencia, la convergencia de las estrategias de la gran empresa con el territorio, de acuerdo con Vázquez Barquero, depende de la procedencia y arraigo de las empresas y de la forma de organización territorial del lugar en que se establecen. Es obligada, en este proceso, la formulación de un plan de desarrollo local al que las empresas podrían adaptarse por su estrategia de inversión. Implica, incluso entre los países periféricos, generar una estrategia de desarrollo endógeno que sea compatible con las expectativas de inversión de las grandes empresas innovadoras. $\mathrm{O}$ sea, redefinir las políticas del desarrollo en términos de la acción de las empresas y su articulación con las organizaciones locales.

En ese contexto, el mismo Vázquez Barquero (1997) supone la posibilidad de formación de un enclave, cuando la inversión de la gran empresa no confluye con las expectativas de vida del lugar en que se localiza. En términos de un ámbito local implicaría que los efectos de la gran empresa ante el desarrollo pueden ser insuficientes o generar disfunciones, que restringen la capacidad de desarrollo en la zona en que se espera un efecto de difusión regional. 
Es una imagen que corresponde más a la situación de las áreas periféricas de la economía actual, donde la expectativa del desarrollo, incluso como iniciativa, se transmuta en un fracaso.

En estos casos las grandes empresas se identifican por su efecto externo, por su escasa vinculación con el sistema productivo local. Los vínculos operan con proveedores y clientes localizados o procedentes de otras regiones. Se genera un dualismo espacial entre el crecimiento del centro productor y el deterioro de las condiciones de vida de su entorno.

Asimismo, la gran empresa trasnacional sólo entabla relaciones de tipo asalariada y que acaban por descalificar y desvalorizar la mano de obra nativa al ofrecer salarios relativamente más elevados. La emigración crece en tanto que se reduce el desarrollo de las áreas rezagadas.

En este contexto, la gran empresa transnacional estructura mecanismos de absorción y extracción de recursos locales, humanos y materiales, cuya riqueza creada se envía a otras regiones. La capacidad empresarial se reduce para los productores nativos y sus aspiraciones de competencia se debilitan en el mercado.

A su vez, las empresas proveedoras y subsidiarias ocupan una posición subordinada, en tanto que las funciones de dirección, contratación, comerciales e innovación las centraliza la gran empresa. La inserción de las empresas proveedoras y subsidiarias en el tejido productivo local es mínima; y es escasa la relación entre los productores locales y la dinámica estructurada alrededor de la gran empresa.

En resumen, cuando el crecimiento y la riqueza generada por la actividad de mayor dinamismo en un área se trasladan hacia otras zonas y se desaprovechan las potencialidades endógenas del lugar, exportándolas a las áreas centrales, se da una situación de enclave.

Se habla, inclusive Vázquez Barquero, de una situación característica de las áreas periféricas convertidas en economías de extracción, donde las filtraciones reducen el impulso inicial de difusión de las grandes empresas establecidas en la localidad.

La posibilidad de convergencia de las estrategias de inversión de las grandes empresas transnacionales con las expectativas del desarrollo local pueden, entonces, en contextos periféricos, derivar en condiciones de escasa difusión y articulación con la economía del entorno en que se instalan. La presencia de la gran empresa no se traduce en resultados endógenos. El corolario del desarrollo polarizado en ámbitos locales se desvirtúa como la forma de un enclave.

La acción de la gran empresa transnacional en espacios periféricos, ante las expectativas del desarrollo local, se puede traducir, en efecto, en una formación social de enclave; pero además, en el actual contexto ad- 
quiere un significado específico, por su distinto contenido histórico y espacial, bajo la figura de un enclave internacional (Martínez, 2006).

\section{Las políticas públicas}

En Lázaro Cárdenas existen todavía fuertes desafíos y persisten diversas dificultades en materia de desarrollo regional. En síntesis, se ha vuelto característica y permanente la poca articulación social y de escaso enlace de las actividades económicas. Se ha vuelto característica del municipio la segmentación social y del territorio frente al predominio del área industrial y urbana, determinada por las empresas fuertes, concentradas en la metal-mecánica e integrada al mercado extralocal y mundial; a su vez, con efectos excluyentes para el resto de los pobladores tanto de la región costera como al interior del área administrativa de Lázaro Cárdenas.

Desde 1970 la zona ha pasado por diversas propuestas de política de desarrollo. El área de la costa michoacana ha estado sujeta a fluctuantes replanteamientos de integración regional. Asimismo, ha enfrentado cambios intensos en la configuración territorial.

La constitución territorial actual del municipio es resultado de varios proyectos instrumentados durante los años setenta y ochenta, con una fuerte presencia de inversión y gestión estatal -inclusive autoritaria y burocrática- y con una intención de defensa nacionalista y de promoción, integración y fortalecimiento del mercado interno. Se pretendía la incorporación de una zona marginada y excluida con respecto al mercado nacional, a partir de la construcción de un área industrial y de una ciudad. De modo persistente, en todas las propuestas aplicadas para el desarrollo regional, la industria siderúrgica y la actividad portuaria han implicado la fuerza principal del desarrollo esperado.

Entre la crisis de los años setenta y las restricciones al Estado como promotor del desarrollo, en los años noventa las políticas regionales se limitaron a consolidar la estructura social y económica existente, edificada en las décadas anteriores. Hacia la primera década del presente siglo, se mantuvo una política orientada hacia una mayor determinación por el mercado externo y en el estímulo de un crecimiento dado desde afuera respecto a las necesidades del área.

\subsection{El gobierno federal y el gasto público}

La presencia del gobierno federal en el municipio ha sido intensa y de constante presencia a través de la intervención del Estado y la permanente aplicación del gasto público federal en la construcción de infraestructura industrial y urbana, y en la actividad económica a fin de asegurar las 
condiciones para el crecimiento de las grandes empresas ligadas al mercado mundial.

De ostentarse como un agente omnipotente durante los años precedentes a la década de los noventa, el gobierno federal se retiró como el principal responsable y promotor del desarrollo regional y procedió a replantear las condiciones de apropiación y gestión territorial en torno a la gran empresa y a la internacionalización del capital.

Luego del redimensionamiento y la reestructuración de las grandes paraestatales en la segunda mitad de los ochenta, después de la privatización de la infraestructura industrial y la renuncia al intervencionismo estatal, la actividad socioeconómica fue transferida a manos y bajo la acción de la empresa privada de alcance nacional y mundial. No obstante, la acción del gobierno federal no desapareció en modo absoluto en la localidad.

El gobierno federal ha mantenido presencia -aunque restringida- en lo económico, comparada con los niveles de inversión que se aplicaron en los años setenta. Incluso, luego de la persistencia que implicó el gasto federal en el Programa de Puertos Industriales en los años setenta y ochenta, mantuvo la presencia con el Programa de Desarrollo de la Costa de Michoacán, 1992-1994 y el Programa de Desarrollo Integral para Lázaro Cárdenas, Mich., 1998-2000.

Entre los intervalos de estos programas, de irregularidad en el flujo del gasto público federal en el primer decenio del presente siglo, se siguen aplicando diversos recursos, mediante programas de acción social y económica lo mismo que a través del gasto público federal programado para los estados.

La presencia del gobierno central y la aplicación del gasto público en la zona, de constante presencia y de montos significativos, se puede caracterizar en tres periodos: 1) entre 1965 y 1982 de intensa intervención económica y creciente gasto público; 2) de 1983 a 2000 con el retiro de la presencia económica, de flujos irregulares y decrecientes del gasto público, y 3) en el intervalo de los gobiernos federales de alternancia panista, donde se sostiene la presencia del gasto público, aunque en un contexto de descentralización administrativa y sin un marco programático de contenido nacional.

La figura del gobierno federal a través del gasto público se sigue orientando al crecimiento y ampliación de la infraestructura portuaria e industrial, en el marco de la internacionalización del capital y con la expectativa de una mayor presencia del puerto Lázaro Cárdenas como punto de enlace en la cuenca comercial del Pacífico. 


\subsubsection{Entre 1965 y 1982}

La inicial conformación de la zona por la vía del crecimiento industrial comenzó a fraguarse en los años cincuenta a través de la Comisión de Río Tepalcatepec-CRT, constituida en 1947- (Barkin y King, 1970; Godau, 1982; Minello, 1982). En 1960 se instituyó la Comisión del Río Balsas (CRB, 1965) que promovió el Plan de Industrialización de la Costa del Pacífico.

Mediante la inversión pública federal, entre 1964 y 1972 el proyecto consideró la construcción de una hidroeléctrica, un distrito de riego, un complejo siderúrgico para explotar los yacimientos de mineral de hierro Las Truchas, un puerto y diversas vías de acceso a la zona. La hidroeléctrica José María Morelos (La Villita), los canales de riego y las vías de comunicación fueron los primeros componentes edificados por la CRB.

A partir de 1973 se construyó la paraestatal Sicartsa y en 1976 comenzó a operar, y con ella se edificó la ciudad nueva. Desde 1973 se estableció el Fideicomiso para el Desarrollo de Ciudad Lázaro Cárdenas Las Truchas (Fidelac) como la entidad paraestatal encargada del diseño y construcción de las obras de urbanización y vivienda. En la década de los setenta se sucedieron numerosas y cuantiosas inversiones públicas en infraestructura de comunicaciones, industrial y urbana.

Con la crisis económica de 1976, al inicio de operaciones de la fase uno de Sicartsa y con el cambio sexenal de gobierno, se pospuso la construcción de la segunda etapa. En vistas de la situación de crisis económica nacional se gestionaron recursos con el Banco Mundial a fin de obtener créditos $\left(685^{\prime} 398,000\right)$ para la construcción (entre 1978-1981) de obras urbanas y el impulso industrial con base en el sector siderúrgico.

Con el renovado poder de la federación en la zona, como parte del convenio financiero con el Banco Mundial se definieron los límites de la llamada Zona Conurbada del Río Balsas y las funciones de su respectiva Comisión de Conurbación.

Asimismo, durante el auge petrolero de fines de los setenta y principios de los ochenta, con el flujo de recursos federales entre 1980 y 1982, se redefinió la política regional con la inclusión del municipio en el Programa de Puertos Industriales, para sobreponerse con las expectativas de una integración mayor al mercado mundial.

Con cuantiosos recursos federales, como parte del recinto portuario desde 1979 se continuaron e iniciaron diversas obras que darían contenido al puerto industrial. Se restableció la edificación de Sicartsa, también se comenzó a construir la planta de fertilizantes, los silos de grano, los depósitos de petróleo, las empresas de la metal-mecánica y las obras iniciales del puerto de altura y del parque industrial. 
Durante el periodo de edificación de la infraestructura básica del complejo portuario industrial y de la zona urbana, el gobierno federal y su política regional se sustentaron en incentivos a la descentralización industrial en función de una creciente inversión pública, sostenida por el endeudamiento externo y, en el segundo lustro de los años setenta, además por el flujo de divisas petroleras.

\subsubsection{De 1983 a 2000}

A comienzos de 1983, y en el cambio sexenal del Poder Ejecutivo federal, fue ineludible -desde 1982 y en estricto contenido desde 1976- la presencia de la crisis. En el municipio se suspendió todo proyecto regional de participación federal. No sólo de tipo industrial y urbano, también los planes de ampliación del área de irrigación agrícola que buscaban complementar y equilibrar la situación económica del municipio.

El gobierno de Miguel de la Madrid se propuso revisar el principio de la rectoría del Estado y la coexistencia de los sectores público y privado. Implicó un periodo crítico y de indecisión en política industrial hasta 1984. Además de enfrentar las consecuencias de la crisis -sólo aliviada por los recursos petroleros y de endeudamiento hasta 1981-, fue el intermedio para una serie de acciones posteriores que comprometieron el fin de las estrategias de programación con propósitos nacionales; y que para la localidad orientaron hacia el fortalecimiento de la inversión externa y privada, y la liberación del mercado (Hiernaux, 1991).

A pesar de la situación de crisis, el gobierno de Miguel de la Madrid decidió destinar recursos para concluir los proyectos comprometidos para la zona. En términos industriales, el caso más evidente fue la decisión de concluir la edificación de la segunda etapa de Sicartsa, que se suspendió en 1976, reiniciada y otra vez suspendida en 1979, y luego otra vez en 1981 y 1983; hasta que -tras reprogramarse entre 1984 y 1985- fue concluida parcialmente y comenzó a funcionar en noviembre de 1988.

En la década de los noventa y con la acción del gobierno federal se desincorporó la propiedad pública sobre la infraestructura productiva. El control de la gestión y propiedad sobre los soportes productivos principales en la localidad se dejó cada vez más a la lógica de la iniciativa privada, en manos de los grandes consorcios y del mercado mundial.

En la zona, 1985 marcaría el inicio de una segunda oleada de acciones destinadas a consolidar a las grandes empresas fincadas y aún consideradas centrales para la economía local. Luego de culminar la construcción básica de la infraestructura industrial, se tomaron resoluciones orientadas a la depuración financiera, administrativa, comercial, laboral y de rehabilitación tecnológica de las paraestatales integradas, para que desde marzo 
de 1990 se anunciara su paulatino proceso de privatización (Martínez, 1992a y b).

Después del Programa de Puertos Industriales implantado en los primeros años de los ochenta, el Plan de Desarrollo de la Costa Michoacana 1992-1994 fue el proyecto subsecuente con una voluntad política determinada desde el gobierno central, con un renovado flujo de recursos federales y con un perfil institucional. Existió un intermedio previo, sin un contenido de planeación sistemática, en el que tomó dimensión -en los hechos- la reestructuración y privatización de las paraestatales, decidido y negociado desde el gobierno federal.

El Plan de Desarrollo Costero se estableció alternativamente, luego de un lapso de incertidumbre delimitado en 1989 por las acciones de privatización de la vida socioeconómica en el municipio. El programa de la costa se estableció con una vigencia de tres años para el ejercicio de los recursos aportados por la federación. A partir del objetivo general de fijar las bases de un nuevo desarrollo en la región, se elaboró un único diagnóstico para los siete municipios involucrados (Aquila, Arteaga, Coahuayana, Coalcomán, Chinicuila, Lázaro Cárdenas y Tumbiscatío).

En medio de la diversidad de proyectos planteados en el ámbito local, la presencia de la inversión pública era aún significativa. En particular para Lázaro Cárdenas -que concentraba $72.5 \%$ de los establecimientos industriales de la región costera- los recursos se aplicaron en 129 proyectos, de los cuales $88 \%$ fueron impulsados por parte del sector público federal y el resto por el privado.

En la composición de la inversión se denotaba una mayor atención del gasto público en proyectos generadores de servicios; mientras que la inversión privada se ligaba principalmente a la actividad industrial. Aun cuando eran menos los proyectos productivos impulsados con recursos privados que los de inversión pública, la empresa privada se concentró en el rubro de su interés.

A pesar de la expectativa inmediatista que se señalaba en los proyectos de inversión de 1992 a 1994, los principios y normas programáticas se siguieron aplicando entre los ańos 1995 y 1997, cuando se interpuso un nuevo vacío de política regional y se instituyó desde 1998 con las reformas estatales para la administración descentralizada de los ayuntamientos y que coincidió, luego, con el Programa de Desarrollo Integral para Lázaro Cárdenas (PDILC) del gobierno federal de Ernesto Zedillo.

Luego de una pausa de tres años sin una propuesta de relativa coherencia para el desarrollo de la zona, el gobierno zedillista instrumentó en 1998, y con un esquema enmarcado en los proyectos de inversión de las grandes empresas establecidas en el recinto portuario y concertados por la Secretaría de Desarrollo Social (Sedesol), el Programa de Desarrollo 
Integral de Lázaro Cárdenas, Mich, 1998-2000. Por primera vez en el municipio el sector privado lograba una presencia superior que la del gobierno federal en materia de inversión, con base en la promoción de sus proyectos de inversión a través de un programa de desarrollo con carácter institucional y regional.

Durante los tres años de vigencia del Programa, se preveía una inversión total de 10,227 millones de pesos para un conjunto de 139 proyectos de inversión sociales y productivos en la zona. A diferencia de los periodos precedentes, estos montos se reunieron mediante una creciente participación de la inversión privada, que se mostró predominante con respecto al gasto del gobierno federal. En particular en términos de las cantidades de financiamiento, la iniciativa empresarial aportó 64\% del total para la instrumentación del Programa.

\subsubsection{Los gobiernos de la alternancia}

Con la alternancia del Ejecutivo federal, primero Vicente Fox y luego Felipe Calderón, paulatinamente ha disminuido la presencia del gobierno federal en la zona, como parte de las restricciones económicas y fiscales, de los consecutivos procesos de descentralización administrativa; así como con los cambios en la composición de los congresos y la alternancia en los gobiernos estatales.

Desde los ańos noventa y como una constante en las políticas públicas federales y estatales orientadas al desarrollo de la costa michoacana, se impuso la práctica de la concertación entre los sectores social y privado y se constituyó como el medio para identificar los proyectos prioritarios para la zona.

Entre 1998 y 2000, ya con la totalidad de la infraestructura portuaria e industrial bajo la gestión de empresarios privados y después de casi una década de vacíos en materia de políticas regionales para el municipio, se instrumentó lo que se llamó el megaproyecto (PDILC), cuyos resultados tangibles fueron la construcción de la autopista Siglo xxı, la identificación de la actividad portuaria como el nuevo eje integrador de la actividad económica local y la expectativa de promover su incorporación, en el marco del TLC norteamericano, a los flujos comerciales de la cuenca del Pacífico.

Al igual que otros planes de desarrollo, las ambiciones del megaproyecto se vieron truncadas entre los cambios sexenales del gobierno federal. Fue hasta 2004, durante el gobierno de Vicente Fox, cuando se concluyó la autopista Siglo XxI como la obra principal del megaproyecto iniciado en 1998 por el gobierno de Ernesto Zedillo, y que disminuyó en 50\% el tiempo de traslado carretero de la ciudad de Morelia a la costa michoa- 
cana; y en esa medida su interconexión con las áreas productivas del centro del país.

Sin una proyección nacional para el desarrollo de la costa michoacana, el gobierno estatal ha asumido en su propuesta de plan de desarrollo las acciones particulares para la zona. El predominio y la prioridad para las grandes empresas en el ejercicio del gasto de procedencia federal se sostienen, como el eje en la aplicación de los recursos públicos, a costa de la pequeña empresa.

La fase inicial de la primera etapa del parque intermodal de la Isla de la Palma, proyecto cuyo objetivo principal fue iniciar la construcción del recinto fiscalizado estratégico orientado a estimular el tráfico internacional de mercancías, lo instrumentó el gobierno del estado con el Fondo de la Pequeña y Media Empresa de 2006. El proyecto se resolvió a través de la Secretaría de Desarrollo Económico mediante el Fideicomiso de Parques Industriales de Michoacán, con un gasto total de 65'655,739 pesos, donde el gobierno federal aporto $50 \%$. Esta primera fase fue entregada en comprobación en marzo de 2008.

Aun cuando se trató de recursos para la pequeña y mediana empresa de la zona, resulta paradójico que se aplicaron con el propósito de establecer un espacio de desregulación y simplificación administrativa y de control aduanero, a fin de estimular la actividad exportadora y promover la atracción de inversiones extralocales. El efecto de la inversión se orientó a una mayor vinculación con la zona Asia-Costa Este de Estados Unidos a través del corredor denominado Naftarailway.

Como parte de la descentralización, en la planeación instrumentada por el gobierno michoacano se carece de continuidad temporal y de metas territoriales de desarrollo; y las propuestas aparecen como respuesta a situaciones de coyuntura; buena parte de los recursos que siguen proviniendo de la federación se disgregan entre los proyectos aplicados en el ámbito estatal.

A partir de que se establecieron las principales navieras una vez resueltas las licitaciones correspondientes, en 2007 se revitalizó la inversión privada a través de las grandes empresas mercantes; así como la inversión federal en la edificación de infraestructura portuaria. Desde el segundo lustro del siglo se programan hacia 2013 un conjunto de inversiones con recursos federales, a fin de adecuar el área al crecimiento del flujo de mercancías y promover el ingreso de inversiones ligadas al comercio internacional.

La Administración Portuaria Integral de Lázaro Cárdenas se constituye, incluso desde 1998 a través del pDLIC del gobierno de Ernesto Zedillo, en la principal entidad reguladora de los espacios de infraestructura al interior del recinto y de la aplicación y gestión de los recursos financieros. 
Con base en esas atribuciones, la APILAC estructuró el Programa Maestro de Desarrollo Portuario 2006-2011, a fin de ordenar y priorizar la inversión de las grandes empresas en los proyectos de consolidación y expansión de sus plantas; así como la aplicación del gasto público federal en la construcción de infraestructura portuaria.

Para el periodo 2006-2011, en la inversión programada los montos de la inversión pública son tres y hasta cuatro veces mayores que el gasto público. Los recursos (8,742 millones de pesos durante todo el periodo) de las empresas se destinan al desarrollo de siete proyectos para construir y ampliar áreas de terminales y movimiento de mercancías. En tanto que el gasto público federal (5,103 millones de pesos para el periodo) se destina a 25 proyectos para infraestructura de transporte, de comunicaciones y de servicios en el área portuaria e industrial.

Además de estas inversiones, con la reciente desincorporación de la Isla La Palma (primer semestre de 2010), el gasto público federal habría de aumentar ante la construcción de la infraestructura para la operación de las nuevas áreas del puerto. De inmediato, por parte de la Kansas City Souhterm se prevé una inversión inicial de 80 millones de dólares para construir el patio multimodal, a fin de desarrollar una megaterminal en 183 hectáreas, y una vez que los terrenos sean restituidos por parte del gobierno michoacano al federal.

Adicionalmente, el gobierno federal ha destinado recursos para proyectos de creación de infraestructura, que aunque se aplican fuera del recinto portuario y con un beneficio poblacional más amplio, constituyen inversiones que tienen efectos importantes en la actividad económica de la zona portuaria e industrial.

Es el caso de la construcción de la autopista Siglo xxi entre 1998 y 2004, de Morelia al puerto Lázaro Cárdenas; así como la edificación de la carretera costera Lázaro Cárdenas a Coahuayana, que ha implicado la participación de varios periodos del gobierno federal dado que la obra no ha sido completada. Aun en 2010, cuando sólo se había terminado el tramo de Lázaro Cárdenas a Playa Azul, el gobierno federal destinó 55\% de los recursos adicionales para el estado de Michoacán en el rubro de construcción y modernización de carreteras (901.9 millones de pesos) para continuar su tendido hasta Caleta de Campos, aún en el municipio de Lázaro Cárdenas. En ese mismo año, como fondo regional se otorgaron 494.7 millones de pesos.

Desde la creación de Ciudad Lázaro Cárdenas como zona periférica de integración al desarrollo nacional, el gobierno federal ha tenido una presencia constante, interviniendo de manera directa hasta los años ochenta en la construcción y operación de áreas industriales, de servicios y en la formación del área urbana; y a partir de los noventa, a través del 
permanente flujo de recursos públicos, proyectando e integrando la zona al mercado mundial.

\subsection{Políticas públicas para la promoción de empresas}

La relativa desarticulación socioeconómica interna tiene un significado estructural e histórico para el municipio Lázaro Cárdenas. Sin embargo, los diagnósticos y análisis oficiosos no reconocen las evidencias de esa disociación económica en el municipio y la prioridad para resolverla como una política regional.

Desde inicios de los años noventa, las políticas sectoriales y regionales instrumentadas para la localidad se han fijado sustancialmente en la transformación de las condiciones de apropiación y gestión, frente a la determinación de los estímulos del proceso de internacionalización.

Como una constante, el crecimiento industrial y las políticas de desarrollo regional se han ajustado a la promoción del sector exportador, la sustitución de importaciones, la reposición de los encadenamientos productivos y la protección de la inversión para alcanzar un lugar competitivo en el mercado mundial.

Desde la expectativa de la apertura comercial y la mundialización de las economías, los puertos comerciales mexicanos revisten gran importancia en las políticas públicas. Es consecuente que los gobiernos michoacanos consideren que el puerto Lázaro Cárdenas aporte una serie de ventajas a los usuarios actuales y futuros, en el marco del sistema portuario mexicano y el comercio marítimo mundial.

\subsubsection{Plan Estatal de Desarrollo}

La integración de un puerto como espacio unitario, competitivo, con capacidad estratégica ante las demandas y necesidades económicas, sociales, culturales y medioambientales del lugar, así como de la economía mundial, se ha visto como un propósito de los últimos gobiernos de la entidad en el contexto de la globalización y el constante crecimiento de la circulación de capital transnacional. El Plan Estatal de Desarrollo, promulgado en febrero de 2003 por el gobierno (2002-2008) de Lázaro Cárdenas Batel (PRD) en el estado de Michoacán ya incorporaba la expectativa de integrar a Lázaro Cárdenas como un puerto ciudad.

En un marco de continuidad, durante el gobierno (2008-2012) de Leonel Godoy Rangel (PRD) se otorgó al puerto Lázaro Cárdenas una prioridad estratégica en el desarrollo económico de la entidad. Además de considerarlo un puerto de importancia mundial en el Pacífico, destaca 
como uno de los principales componentes del corredor industrial Lázaro Cárdenas-Morelia-Contepec.

En el Plan Estatal de Desarrollo 2008-2012 se reconoce que las políticas públicas aplicadas en la zona "no han permeado en la población local y ha dejado mucho que desear en cuanto a sus posibilidades y capacidades para potenciar el desarrollo local y regional” (p. 24), por lo que se busca "reducir y, en lo posible, revertir las tendencias que tienden a convertir a este polo de desarrollo en un simple 'enclave mundial"' (p. 24).

"El Puerto Lázaro Cárdenas debe ser un centro dinamizador de la economía local, regional y nacional, y no un simple espacio generador de riquezas para trasnacionales cuyas matrices e incentivos de expansión se encuentran en el exterior" (p. 24). En torno a ese propósito se propone promover

la diversificación productiva mediante el impulso a pequeñas y medianas empresas industriales y de servicios, con encadenamientos productivos y de proveeduría con las grandes empresas del núcleo metalúrgico y metal-mecánico existente. Se trata, en este caso, de que dichos encadenamientos de valor se desplieguen a través de un esquema de asociatividad competitiva. La aplicación de estrategias enfocadas a generar incentivos para la instalación de nuevas empresas en el recinto fiscal deberá ir acompańada de compromisos por parte de las empresas de consumir insumos locales para fomentar la integración de las cadenas de valor (Plan Estatal de Desarrollo del Gobierno de Michoacán, 2008-2012: 24).

La convergencia entre las grandes empresas establecidas en el puerto con las posibilidades de un desarrollo integral y articulado con las pequeńas empresas y con la vida comunitaria y cultural de la región, aparece como un propósito explícito en las estrategias de desarrollo para los últimos gobiernos michoacanos y con el respaldo de la federación.

\subsubsection{Proyectos estratégicos de inversión}

Los proyectos estratégicos se centraron en torno a la promoción de la actividad portuaria, en particular de las grandes empresas establecidas, y en la atracción de nuevas inversiones de capital ligado al mercado mundial.

En correspondencia con las expectativas fijadas en los gobiernos perredistas del estado, se prevén grandes potencialidades para el puerto en la región, la consolidación del sector minero, de servicios y comercial; el apoyo a las exportaciones de alimentos agrícolas; el desarrollo de plantaciones forestales comerciales y el desarrollo del turismo ecológico.

Particular énfasis se dio al proceso de desincorporación de la Isla Las Palmas, como la principal área de ampliación y reapropiación de infraestructura para la inversión de grandes empresas enlazadas al mercado 
mundial. La desincorporación instrumentada a mediados de 2009 fue comprometida en 2006 por el gobierno michoacano de Cárdenas Batel, y se acompañó de un amplio reclamo social respecto a sus efectos de desnacionalización y de privatización a favor de la empresa estadounidense Kansas City Southern de México. La KCSM construiría una nueva estación intermodal que le permitiría controlar la totalidad del movimiento comercial por ferrocarril del puerto, y que fortalecería su sistema ferroviario en el noreste del país y con el sureste de Estados Unidos para conectarse con la red de la costa este hasta Canadá.

La ampliación de la infraestructura portuaria suponía también una expectativa de diversificación industrial y fiscal del puerto, sobre la base de la gran empresa y una serie de proyectos estratégicos encaminados a apuntalar al puerto como un complejo logístico industrial y comercial, en uno de los principales de México, con grandes atractivos para las rutas este-oeste y norte-sur.

La ampliación y diversificación del puerto pasa, entre otros proyectos, donde están comprometidas grandes empresas, la reestructuración de la terminal de contenedores después de finalizado el proceso de licitación que fue adjudicado a la empresa Controladora y Operadora de Terminales, s.A. de C.v. El proyecto incluye 14 ha que abarcan la actual terminal de contenedores. La empresa podría desarrollar una segunda área de 100 ha, una vez que se haya alcanzado el movimiento de 180,000 contenedores por año. Este movimiento, según estimaciones de la API Lázaro Cárdenas, podría ser alcanzado en seis o siete años. ${ }^{2}$

Asimismo, el puerto se considera el espacio idóneo como plataforma de exportación e importación de automóviles más importante del Pacífico mexicano. La API Lázaro Cárdenas ha destinado un área para movimiento de vehículos, y se planea establecer una terminal de almacenamiento de automóviles. Empresas como Centurión prevén la cesión parcial de derechos de un patio de 15 ha donde se realizaría una inversión conjunta de tres millones de dólares, buscando mover un total de 330,000 autos en los primeros cinco años de operación. Las actividades de Centurión representarían $8 \%$ adicional a los ingresos de la administración portuaria (APILAC, 2006).

Por su parte, la disminución de costos de transportación, a través del fortalecimiento del sistema ferroviario, y de los costos de aseguramiento de mercancías se reflejan en la presencia del Grupo Transportación Marítima Mexicana (TMM) que esperaría una concesión parcial de derechos

\footnotetext{
${ }^{2}$ Esta terminal tiene dos grúas de marco, un patio de 14 ha, pavimento de concreto hidráulico, espuelas de ferrocarril, muelle con $14 \mathrm{~m}$ de profundidad y 396 tomacorrientes para el manejo de contenedores refrigerados. Actualmente, la terminal ofrece una productividad de 25 contenedores por hora/grúa.
} 
de 5 ha donde buscaría crear un vehicle processing center (VPC). De acuerdo con TMM, este puerto tendría el potencial para manejar 165,000 automóviles al año y estaría dispuesto a invertir los recursos necesarios.

En el ámbito industrial y con vistas a consolidar la actividad de las empresas siderúrgicas en las terminales de usos múltiples (TUM), se realizarían cambios en la operación de la Terminal I, concesionada a Mittal Steel. La empresa proyecta cumplir como meta el manejo de 700,000 toneladas de carga y mantener un crecimiento de $1.5 \%$ y hasta de $10 \%$ anual. En Sicartsa/Mittal, la Terminal II, se proyecta comercializar los servicios de la terminal como una entidad pública donde puedan trabajar distintos operadores.

En particular los gobiernos perredistas de Michoacán se muestran interesados en instalar un recinto fiscalizado estratégico (RFE) que le imprimiría mayor dinamismo al transporte intermodal, así como a la gestión portuaria. Adicionalmente existe el proyecto de construir un aeropuerto internacional de carga que permitiría consolidar operaciones aéreas de entrada y salida de mercancías al puerto. Considerando los ritmos de crecimiento de operación del puerto, en el Plan Estatal de Desarrollo se propone la construcción de un aeropuerto en Lázaro Cárdenas que apoye el fomento planeado para esta zona, en términos turísticos comerciales y de negocios.

En este escenario se percibe un relativo vacío de planeación del desarrollo en la región. Las acciones programadas se remiten a los proyectos de inversión en marcha de los consorcios empresariales y que, en general, se condicionan a la disponibilidad de la infraestructura que a través de la administración portuaria se les otorga. A pesar de los montos de inversión destinados, por la amplitud y diversidad de agentes sociales en concertación y por la coherencia de sus expectativas de crecimiento, la planeación continúa como una acción de corto plazo y cuyo ámbito de influencia se vuelve más restrictivo, limitado a la ciudad. El ámbito de incidencia de las políticas de desarrollo se estrechan al área de la ciudad.

En el esquema de planeación que se instrumentó a partir de los años noventa y que sigue vigente para Lázaro Cárdenas, el Estado abandonó el protagonismo como principal inversionista y se constituyó en el concertador, orientador y regulador de las acciones para el crecimiento de la zona y dejó de asumir una perspectiva de desarrollo local en el largo plazo. En esa propuesta, la lógica empresarial y del mercado se consideran la vía generadora de inversión, de empleos y, en consecuencia, de ingresos y de bienestar social. Para ello se refuerza la acción de la industria, el comercio y la capacidad de financiamiento como normas para una mayor homogeneidad y desarrollo regional. 
En esos términos, la preocupación del Estado es provocar la mejor asignación de los recursos públicos y privados a través de un mercado interno cada vez más ligado al exterior. La integración territorial de la zona en términos programáticos busca incorporar la economía del área a la dinámica internacional, a partir del crecimiento de las principales industrias y con una mayor integración productiva vertical y horizontal. Se trata de criterios similares a los aplicados en la política regional de los años setenta, inclusive ochenta, pero con el nuevo ingrediente contextual de la recurrente crisis, la internacionalización y la reestructuración y modernización industrial; pero además sin la participación del Estado a través de la inversión pública.

Se imponen y consolidan cambios en las formas de apropiación y gestión del territorio que, inclusive reconociendo su situación de desarticulación de la economía local, buscan disminuir los efectos negativos y potenciar sus posibilidades en el nuevo contexto del capitalismo nacional y mundial. La reordenación del territorio se sigue sustentando en la lógica y posibilidad de reconstruir enlaces verticales y horizontales en torno al bloque industrial metal-mecánico y la renovada actividad portuaria. Inclusive las políticas de desarrollo e infraestructura social y de fortalecimiento municipal y regional apuntan hacia ese propósito, considerado sustancial.

\section{El circuito de las grandes empresas}

La industrialización en Lázaro Cárdenas vista como el conjunto de la infraestructura edificada y que funciona como un complejo, se organizó de modo preconcebido bajo la forma de puerto industrial. Se constituyó, con base en la inversión pública federal, como un área exclusiva para la producción y transferencia de mercancías, y con el fin de generar condiciones de localización industrial y desconcentración económica. Para ello, en torno a la gran empresa como entidad dinámica, abarcó desde instalaciones portuarias y marítimas, accesos de comunicación terrestre, hasta áreas para un parque industrial. Una amplia infraestructura al servicio de las empresas establecidas en el recinto portuario y que debiera funcionar de modo articulado a través de los vínculos entre las plantas fabriles. En ese sentido, las instalaciones del puerto industrial estarían dispuestas a la generación de empresas de menor tamaño, la diversificación de la economía y el incremento de las exportaciones.

En cuanto complejo industrial, el área se puede reconocer por la infraestructura edificada y cuya instalación suponía la integración de un conjunto de grandes empresas que habrían de equilibrar y dar contrapeso a la fuerte incidencia que desde su origen ejerce la actividad siderúrgi- 
ca en la localidad. El propósito ha sido provocar enlaces inmediatos de empresas mayúsculas en tamańo y con capacidad de atraer a otras de menor dimensión como proveedores o consumidores de los productos generados.

Las condiciones de organización de las empresas establecidas en el área cambiaron sustancialmente en los noventa, por sus vínculos productivos y comerciales fuera de la localidad y en función de las diferentes estrategias de integración industrial. Las principales empresas emplazadas en el puerto se consolidaron como parte de un conglomerado de negocios, separado de la economía local y con presencia nacional e internacional en diferentes actividades (extracción, procesamiento, servicios, comercio).

El proceso de privatización de las empresas paraestatales instaladas en la localidad, ejecutado a inicios de los noventa, fue la coyuntura que precipitó un amplio efecto de centralización de capital, a través de fusiones, adquisiciones y nuevas inversiones. Se replantearon las condiciones y formas de organización industrial, a la vez que se diversificó y extendió el ámbito para su integración.

Ante los impulsos provocados por la internacionalización del capital, los cambios se manifestaron en las formas de integración de los grandes capitales privados que operan en la localidad, en la reasignación del mercado, de las actividades productivas y en la posesión de las reservas de recursos naturales. Las formas de organización e integración industrial de las empresas centrales se construyeron hacia el ámbito extralocal a partir de los vínculos productivos, tecnológicos y comerciales estructurados frente a la actual fase de la internacionalización. Con base en la articulación en corporativos privados con perfil transnacional, ajenos a la localidad por su origen, con distinta trayectoria y posición competitiva, y que como agentes de la internacionalización desarrollaron estrategias diferenciadas para expandirse en el mercado.

Para cada consorcio establecido en el puerto se perciben expectativas y capacidades de competencia diferenciadas, que en términos territoriales definen distintas condiciones de expansión e integración industrial de la localidad al exterior. Las disyuntivas de integración y expansión industrial de las empresas, ahora vistas como eslabones de un conglomerado de negocios privados y trasnacional, no son semejantes. Aparecen diferencias de acuerdo con el origen y trayectoria del grupo empresarial, en el control centralizado sobre el conjunto de las filiales -y al que se incorporan las empresas locales-, por la diversidad de negocios que se aglutinan en torno al grupo gestor y en términos de la lógica de expansión y concentración de los capitales.

La presencia de los consorcios, desde su posicionamiento en las plantas industriales establecidas en la zona, se extiende preferentemente a los 
niveles nacional e internacional $y$, en consecuencia, aparecen desligadas de las condiciones del desarrollo local, a pesar de que sus plantas en el puerto son una referencia importante en el crecimiento del conjunto corporativo. Antes que corresponder con las condiciones de la localidad, se adecuan desde su trayectoria particular a las condiciones de la competencia ante el mercado nacional y mundial.

De ese modo, en este circuito económico se pueden identificar grupos que se extienden y consolidan como prioridad en el mercado nacional, como condición para crecer al exterior, en especial en la distribución de sus productos. Se trata de empresas con arraigo nacional, con estrategias diferenciadas por su alcance regional en el país.

Por otra parte, en el área también se localizan emplazamientos industriales con los que un corporativo extranjero estructura una red planetaria de entidades empresariales especializadas y eslabonadas productiva y comercialmente, aunque sin descuidar la competencia nacional a la que se asimila y extiende, y asumiendo una fuerte capacidad de competencia internacional.

Desde la localidad y en función de la organización de las principales industrias ante el proceso de internacionalización, se estructuran distintas estrategias de integración extralocal. En la caracterización de los márgenes de expansión territorial, por las áreas en que un consorcio logra presencia e incorpora a sus filiales bajo un mando centralizado, es significativo el origen, arraigo y trayectoria del grupo, el tipo de empresas posicionadas en cuanto al producto y por la superficie de concurrencia.

\subsection{El área portuaria}

El puerto cuenta con la infraestructura necesaria para responder a las necesidades de comercio internacional existentes en la actualidad. Se proyecta como un centro logístico de distribución de carga y plataforma de exportación/importación. Del conjunto de empresas, desde los primeros años de la edificación del polo de desarrollo, el complejo siderúrgico continúa siendo la parte dinámica, además de su importancia sectorial aporta el monto mayor de carga portuaria. A su lado crece la infraestructura para el tráfico de contenedores y de vehículos automotores, junto con las áreas aduaneras. En todos los casos predomina la ausencia de enlaces con empresas locales, inclusive al interior del recinto portuario.

La reactivación de la terminal de contenedores permitió un crecimiento exponencial de la operación comercial; mientras que en el año 2002 se movilizaron menos de 200 contenedores (TEus), al cierre de 2007 el movimiento superó los 270,000; respecto al desplazamiento de vehículos, 
ascendió a 110,000, mientras que a inicios del siglo era completamente nulo el movimiento de unidades.

De acuerdo con los reportes de la Secretaría de Comunicaciones y Transportes, entre 2002 y 2007 el puerto tuvo un incremento de $22 \%$ en cuanto a los volúmenes de carga manejados, con una tasa de crecimiento promedio del $3.4 \%$ anual. Estas circunstancias hicieron que el puerto registrara el mayor crecimiento en el contexto nacional en movimiento de contenedores y de vehículos. De acuerdo con el gobierno, Michoacán ocupa el primer lugar en movimiento de vehículos en el Pacífico mexicano y el segundo lugar en el ámbito nacional.

En 2008 el puerto de Lázaro Cárdenas estableció una nueva marca en movimiento de carga, estimada al cerrar el año en 22'128,000 toneladas y se colocó como el principal de 22 puertos que integran el Sistema Portuario Nacional. Este récord se logró a pesar de que en 2008 hubo una caída drástica de importación de carbón mineral por la Comisión Federal de Electricidad (CFE), que maneja, a través de la empresa privada Carbonser, una terminal de hasta seis millones de toneladas de carbón, y sólo operó con un millón, ante problemas de precios.

De acuerdo con la Secretaría de Comunicaciones y Transportes, 17\% del comercio entre México y Estados Unidos se mueve por Lázaro Cárdenas con un valor de 70,000 millones de dólares. Por el tipo de carga, $53 \%$ son materias primas para la industria acerera y eléctrica (hierro y carbón mineral); 19\% de carga en contenedores (artículos electrónicos, autopartes, acero inoxidable, perecederos, cerámica, papelería, línea blanca, maquinaria y neumáticos, entre otros); $16 \%$ combustóleo, gasolina y diesel, y $12 \%$ productos agrícolas a granel, principalmente trigo y maíz.

El producto que cobra importancia en el puerto es el embarque y desembarque de automóviles, que compite con los puertos de Veracruz y Manzanillo. En 2003 se descargaron 4,500 vehículos para llegar en 2007 a 114,276 y colocarse en el primer lugar de puertos nacionales en el Pacífico, luego de que las armadoras cambiaron sus operaciones de Manzanillo a Lázaro Cárdenas. En 2008 se estimó llegar a 140,000 vehículos de las marcas Chevrolet, General Motors, Mazda, Toyota, Izuzu y Matiz.

Esta variedad de mercancías comenzó a generarse en 2004, cuando operaron diversas firmas navieras, Maersk Sealand, Hapag-Lloyd, APLMeritus, Cosco Lines, Evergreen, CSAV, CCNI y Hamburg Sud. En 2007 arribaron 774 buques cargueros, mientras que a noviembre de 2008 atracaron 1,046 buques, la mayoría de entre 300 y 347 metros de eslora (largo), entre ellos los que la naviera Maerks comenzó a manejar a partir de octubre de 2008.

La rápida consolidación del puerto en el manejo de carga de contenedores, al pasar de 1,646 en 2003 a unos 450,000 al cierre de 2008, llevó 
al consorcio asiático Hutchison Port Holding a proyectar la construcción de una megaterminal especializada. En la primera etapa, en 2006, se invirtieron poco más de 200 millones de dólares y tiene prevista una inversión superior para la segunda etapa, a fin de lograr manejar dos millones de contenedores al año.

La empresa ferroviaria Kansas City Souhtern de México (КCSM) opera el corredor intermodal Lázaro Cárdenas-Kansas City, por lo que se esperan inversiones por 80 millones de dólares para la terminal ferroviaria de contenedores más grande de México, junto a la que será también la aduana más grande del país.

Se estima que antes de 2015, el puerto de Lázaro Cárdenas estará operando unos 6 millones de contenedores anuales y las navieras usarán el puerto para hacer llevar por ferrocarril mercancías procedentes de Asia hasta la costa este de Estados Unidos.

Entre las estrategias financieras que ha ejecutando la API Lázaro Cárdenas, de acuerdo con el Programa Maestro de Desarrollo Puerto Industrial y Comercial Lázaro Cárdenas, se encuentra la aplicación de los recursos para el mantenimiento e inversión en infraestructura, incluye mantenimiento de la maquinaria y equipos existentes; además del salario del personal especializado de la terminal de contenedores; tarifas integradas de acuerdo con el tonelaje de registro bruto de la embarcación. Con la tendencia actual de los grandes buques se opera con un balance superavitario y se cuenta con los recursos para los gastos de inversión y corrientes; en los contratos de cesión parcial de derechos, se establece actualizar anualmente el monto de la contraprestación a los usuarios, tomando como base el contrato respectivo; asimismo, inversiones en tecnología para optimizar las actividades y los servicios portuarios.

\subsection{Las empresas siderúrgicas}

Entre las grandes empresas establecidas en el puerto, el complejo siderúrgico sigue siendo uno de los íconos que identifica a la zona. La actividad industrial de la ciudad portuaria se realiza sobre todo en torno a la siderurgia y como la principal operadora de carga. El puerto alberga la Siderúrgica Lázaro Cárdenas-Las Truchas, edificada en los años setenta como paraestatal en dos plantas (Sicartsa I y II), luego fraccionada en cuatro plantas y la mina para privatizarlas en 1993 (se constituye Sicartsa para el Grupo Villacero e Ispat Mexicana como antecedente de lo que hoy es Mittal). En 2006 Acelor Mittal adquiere Sicartsa y a inicios de 2010 se fusionaron las cuatro empresas para reconstituir el complejo siderúrgico. Las empresas Sicartsa, Sersicartsa, Asssa, Atibsa y Mittal Servicios se fusionan en una sola empresa, la ArcelorMittal del Hierro, s.A. de c.v. con 
poco más de 3,500 obreros sindicalizados, otro tanto más de trabajadores de confianza y alrededor de un millar empleado a través de subcontratistas y filiales.

Sicartsa Mittall, productos largos, produce alrededor de 2.3 millones de toneladas anuales de acero líquido y 1.75 millones de toneladas en productos terminados, varilla corrugada y alambrón. Por su parte, Mittal, productos planos, produce más de dos millones de toneladas de acero, sobre todo planchón. En conjunto, la ArcelorMittal del Hierro se convierte en el mayor productor siderúrgico de México, con una capacidad de producción anual de 6.7 millones de toneladas y se sitúa como el principal exportador de acero en México.

Para el tráfico portuario es la empresa Servicios Siderúrgicos Integrados (Sersincartsa), también propiedad de ArcelorMittal, la que opera el muelle con que se maneja la carga para los insumos de la industria del acero. Entre los productos que opera la terminal están alambrón, arrabio, bentonita, carbón, coque, chatarra, dolomita, caliza, escoria, fierroesponja, mineral de hierro, palanquilla, pellet, pellet feed, planchón y varilla corrugada, y que en conjunto representan más de $50 \%$ de la carga en el puerto.

\subsection{Empresas de logística comercial}

La reestructuración de las rutas navieras internacionales involucró a Lázaro Cárdenas como área de interacción e integración territorial nacional con respecto al mundo. El reacomodo de los trayectos exigió al puerto eslabonamientos de tráfico comercial que operen con sistemas flexibles y de justo a tiempo, atentos a la oportunidad y puntualidad de los envíos y como enlaces entre las plantas externas y las nacionales. El puerto Lázaro Cárdenas, a través de las grandes navieras, opera con estándares internacionales de productividad, calidad, costos y seguridad. Sus principales competidores son los puertos estadounidenses en el Pacífico próximos a la frontera norte de México. A excepción de los grandes puertos de California, Lázaro Cárdenas cubre movimientos de carga superior o similar que otros puertos del Pacífico en el continente americano.

El puerto Lázaro Cárdenas ocupa el primer lugar en movimiento de carga mexicana, con un crecimiento promedio del 14\% anual en la década desde los noventa. En el Pacífico mexicano atiende las necesidades del mercado interno, mediante cabotajes, y los servicios de tráfico de altura de comercio exterior. Se encuentra entre las principales rutas del comercio marítimo mundial, en especial el eje horizontal que recorre Asia, América y Europa.

En este marco el puerto incorpora a los más grandes operadores de puertos marítimos de altura. Uno de ellos es Hutchinson Port Holdings, 
Ltd., que planeaba una inversión de 290 millones de dólares para los próximos 20 ańos y crecer la terminal de atraque existente en 1,481 metros y un nuevo canal con 18 metros de calado, con capacidad para recibir cuatro buques extralargos (ULCV) al mismo tiempo. Las estrategias de crecimiento prevén la expansión del patio de contenedores de 15 a 102 ha, para una capacidad estática de 70,000 TEU y una capacidad dinámica de dos millones de TEU, generando hasta 2,900 empleos. Tres de las empresas más grandes de transporte naviero, CP Ships, APL y Maersk Sealand, tienen servicio regular a Lázaro Cárdenas.

A través de los enlaces ferroviarios y de carreteras, el puerto tiene conexión directa a la frontera norte de México, desde donde se parte a Estados Unidos, conectando con los 17 estados localizados en el noreste de ese país y que representan 60\% del PIB estadounidense. Esta ruta, desde el puerto de Lázaro Cárdenas a la costa este de Estados Unidos, es alternativa para el transporte multimodal proveniente de Asia, representa un ahorro en los costos de la cadena de suministro, en los tiempos de gestión portuaria y recorrido, con respecto a los puertos del estado de California: Long Beach y Los Ángeles.

El puerto, además de estar conectado con 10 carreteras de cuota que lo comunican con centros importantes del país, se encuentra acoplado al Valle de México con la ruta ferroviaria División Pacífico de Transportación Ferroviaria Mexicana, s.A. de C.V. (TFM) y Kansas Southern, al noroeste con Ferromex, y al sureste con Ferrocarril del Sureste, s.A. de c.v. (Ferrosur).

El principal destino del movimiento interior es el norte y centro del país, particularmente Nuevo León con el transporte de acero y otros insumos que destacan por su peso de carga; así como Tamaulipas, a través de los puntos de cruce hacia Estados Unidos; y sobresalen el Estado de México, Jalisco y la Ciudad de México, como las principales áreas económicas del centro de la república.

\subsection{El recinto fiscal estratégico}

En particular el gobierno del estado de Michoacán se encuentra en proceso de instalar un recinto fiscalizado estratégico (RFE) al interior del puerto, ${ }^{3}$ lo que reforzaría al puerto como ámbito operativo especializado de la gran empresa transnacional con vínculos extralocales.

\footnotetext{
${ }^{3}$ De acuerdo con la Ley de Aduanas, el régimen de RFE consiste en introducir, por tiempo limitado, mercancías extranjeras, nacionales o nacionalizadas a los RFE para ser objeto de manejo, almacenaje, custodia, exhibición, venta, distribución, elaboración, transformación o reparación y se sujetará a lo siguiente: a) no se pagarán los impuestos al comercio exterior ni las cuotas compensatorias, salvo que se trate de las mercancías extranjeras, en los casos previstos en el artículo 63-A de la ley aduanera; b) no estarán sujetas al cumplimiento de las regulaciones y restricciones no arancelarias y normas oficiales mexicanas, excepto las expedidas en materia de sanidad animal y vegetal, salud
} 
Las industrias que podrían establecerse en este tipo de instalación deben, en términos comerciales, estar ligadas a operaciones de importación y exportación, ya sea con productos terminados o materias primas para la fabricación del producto terminado. La expectativa es atraer inversionistas de los diferentes sectores industriales.

Con objeto de apoyar a la pequeña y mediana empresa a desarrollarse en un RFE, se requiere el apoyo del gobierno estatal en cuanto a financiamiento, capacitación en materia de exportaciones y de cadenas de suministro. Sin embargo, dado el tipo y los volúmenes de operaciones, las posibles empresas susceptibles de instalarse en el recinto serían grandes, principalmente del área textil, electrónica y logística; serían industrias localizadas en los alrededores del estado de Michoacán, en las entidades conectadas directamente con Lázaro Cárdenas y por su disposición a importar y exportar entre México y Asia.

De acuerdo con las expectativas del mercado, los clientes potenciales que se podrían interesar en la instalación de centros de transformación dentro del RFE, tendrían dos diferentes tipos de perfil. Por un lado, los que utilizarían el RFE con las ventajas que ofrece como tal, y que no utilizarían la transformación de las mercancías manejadas, sólo aprovecharían la exención de impuestos en tanto las mercancías se encuentren dentro de la instalación. En este grupo estarían empresas de transporte y logística que manejan mercancías de importación de clientes diversos dentro del recinto, realizando actividades de cross dock y consolidación y desconsolidación (en bodegas de distribución propias o rentadas), incluyendo la terminal intermodal de TFM-Kansas Southern, de acuerdo con las cadenas de suministro de cada cliente en particular, para la entrega justo a tiempo requerida. El destino final de estos productos bien puede ser dentro del territorio nacional o en países extranjeros (básicamente Estados Unidos o América del Sur).

Por otro lado, aquellas industrias que aplicarían proceso de transformación a las mercancías que entren al recinto y que utilizarían las ventajas de la categoría fiscalizado estratégico, que permite la transformación. Entre ellas, empresas del sector electrónico, textil, agroindustrial y, en general, el sector maquilador; industrias que pueden recibir mercancías

pública, medio ambiente y seguridad nacional; $c$ ) las mermas resultantes de los procesos de elaboración, transformación o reparación no causarán contribución alguna ni cuotas compensatorias; $d$ ) los desperdicios no retornados no causarán contribuciones siempre que se demuestre que han sido destruidos cumpliendo con las disposiciones de control que para tales efectos establezca el SAT mediante reglas. Además, las empresas que operen dentro del RFE cuentan con la exención del pago del impuesto especial sobre producción y servicios (artículos 8 y 13 de la ley del impuesto especial sobre producción y servicios), del impuesto al valor agregado (artículo 9 fracción 9 y artículo 25 fracción 1 de la ley del impuesto al valor agregado), y también podrán deducir el impuesto sobre la renta de los bienes que se encuentran sujetos a este régimen desde el momento en que se introducen en el RFE mediante las reglas que establezca el sat. 
de importación (sobre todo materia prima) y efectuar únicamente tareas de ensamble o adaptación con partes faltantes. Este valor agregado significa un cambio en la presentación final del producto, por lo que al salir del recinto se considera como otra mercancía, diferente a la que ingresó.

Entre las empresas ya establecidas en el puerto y que han manifestado interés en el recinto fiscal está Transportación Ferroviaria Mexicana (TFM) y Kansas Southern, como líneas ferroviarias que dan el servicio en Lázaro Cárdenas. A su vez, Maersk New Zealand, una de las navieras más importantes del mundo y que actualmente presta servicio en Lázaro Cárdenas, tiene interés en instalar una terminal de consolidación y desconsolidación de carga dentro del recinto.

Estas empresas privadas tienen segura su participación en las instalaciones previstas. Es el caso de la actual terminal ferroviaria del puerto que se encuentra dentro de las instalaciones de la administración portuaria, formada básicamente por una vía sencilla que restringe la flexibilidad de operación, por lo que se encuentra en negociación la reubicación de la terminal en la Isla de Las Palmas, donde se espera disponer de espacio para una terminal completa integrada al complejo a desarrollarse.

Con la instalación del RFE planteado por el gobierno de Michoacán, se pretende también desarrollar un centro de actividades económicas (CAE). Esta figura se comprende como una zona de concentración de actividades económicas, logísticas y empresariales de carácter multifuncional. Es el coronamiento que consolidaría al puerto Lázaro Cárdenas como área para el crecimiento de la gran empresa.

A través del CAE las instalaciones contarían con capacidad de concentración de cargas y de generación de sinergias muy superior a las de las zonas industriales convencionales, con la finalidad de potenciar la calidad de los servicios, diversificación de la oferta, servicios comunes, economías de escala con el uso de infraestructuras comunes, promoción de una imagen comercial a escala internacional, etcétera.

En el marco de esta variedad de proyectos, Lázaro Cárdenas se establecería como el pivote de un espacio de actividades económicas sobre la gran región que tiene influencia (centro, occidente y noroeste del país), poniendo en el mercado toda una serie de espacios para la actividad económica, propiciando una amplia gama de oferta para cada empresa según sus necesidades. La atención es para una amplia gama de establecimientos, con posibilidades de adaptarse a cada tipo de empresa, e inclusive cambiando las instalaciones conforme a nuevas necesidades.

En síntesis, el complejo portuario de Ciudad Lázaro Cárdenas se consolida como el circuito de las grandes empresas en una zona donde opera como enclave en condiciones de internacionalización del capital. En ese contexto ejerce un doble papel, por la infraestructura edificada 
opera como un puerto de enlace comercial y también industrial. Desarrollan capacidades para vincular diversas cadenas productivas que operan de modo fragmentado desde el ámbito nacional y con respecto al mercado mundial, sin incidir positivamente en su entorno a través de enlaces y de economías de escala.

\section{El circuito de las micro y pequeńas empresas}

Una vez que la industria, la actividad portuaria y el crecimiento urbano se consolidaron en Lázaro Cárdenas, se hizo evidente la separación de la economía local ante la lógica de producción de las grandes empresas. Se configuró un extenso circuito socioeconómico que, aunque disociado del área de mayor dinamismo, opera sobre la base de la derrama salarial y la reproducción de la fuerza de trabajo ligada al conjunto de consorcios empresariales establecidos al interior del puerto.

Se trata de un mercado que se sujeta a las fluctuaciones impuestas por los elevados e irregulares flujos de inversión en infraestructura industrial, urbana y agrícola, de una rotación dilatada de capital y con una constante movilidad poblacional, de altos salarios, que aún genera dificultades de abastecimiento, fluctuación en los precios de las mercancías en su mayoría importadas a la localidad y altos rangos de inflación.

El mercado que abastece la demanda interna de alimentos y manufacturas diversas, e insumos agrícolas e industriales, es ajeno a la economía interna. Se trata de un mercado con vínculos extralocales y del que sólo tienen control las grandes empresas a través de sus propias redes de comercialización nacional e internacional.

Es en la planicie donde se reconstituye el principal mercado local, que genera estímulos diferenciados. Se generan áreas comerciales autónomas: el de las industrias, el de abastecimiento urbano (para el consumo individual y de reproducción del trabajo asalariado), el agrícola y el pecuario como actividades desligadas entre sí, con redes comerciales distintas y enlazadas extralocalmente. De modo que a través de la acción mercantil, las condiciones de poblamiento responden a estímulos diferentes y ajenos a las expectativas de integración local.

En las áreas sustanciales de la economía municipal (industrial, servicios y agropecuario) se recurre a circuitos específicos y externos en el comercio. Las actividades productivas se estructuran sin una relación horizontal y, a la vez, determinadas en lo vertical por la acción extralocal de las grandes empresas. En esos términos, en la zona se reproducen áreas de mercado con una lógica separada y desarticulada, principalmente en la planicie como el conjunto poblacional de mayor diversidad y diferenciación social. 
La desarticulación provocada por el mercado incide principalmente en el área urbana y en su área inmediata de influencia. En particular en la ciudad el mercado integra a la población de modo disociado; pero además con pequeños, y en algunos casos nulos, flujos de intercambio con los otros fragmentos de la actividad económica en la zona; y a los que debiera incorporar en una lógica global. Esta situación se refuerza con la acción de las grandes empresas apropiadas y gestionadas en el contexto de la internacionalización del capital y que se ligan a los mercados extralocales.

Por un lado, la fuerza que genera el complejo industrial con impulsos internos se restringe a la demanda de mano de obra, al crecimiento del sector comercial y de servicios, también con nexos externos, y a la expansión desordenada de los asentamientos urbanos sobre las áreas rurales. Se trata de la dinámica que sobre todo se integra al mercado extralocal, mediante la importación y exportación de materias primas y de productos.

Como efecto de la limitada capacidad de difusión económica de las industrias, entre las localidades urbanas se multiplican -bajo formas de la economía informal- diversos establecimientos micro y pequeños de la actividad comercial y servicios, que se alimentan de los ingresos y del trabajo de la población asalariada local y se abastecen con artículos que no se fabrican en la zona.

Es un amplio sector de micro y pequeños negocios, que aun cuando la actividad industrial representa un número menor de unidades económicas que el comercio y los servicios, cuya estructura es más dispersa, la generación de empleos industriales en proporción es mayor. Mientras que en la manufactura cada unidad económica ocupa ocho trabajadores en promedio; en los servicios y el comercio cada establecimiento emplea a tres personas.

Es significativo que en los censos económicos de 1994, 1999 y 2004 la cantidad de empleos manufactureros registrados decrecieron tendencialmente, en tanto que los comerciales y de servicios aumentaron. A partir de los ańos noventa la ocupación industrial representó cerca de un tercio del trabajo formal y disminuyó progresivamente a alrededor de $20 \%$ en 2004.

Desde los años noventa, en la ciudad -el área de mayor interferencia industrial- la economía creció de forma alternada a través de las actividades comerciales y de servicios en mayor proporción. En 1996 la distribución proporcional de los negocios que tramitaron un permiso ante la Tesorería Municipal, muestra que en la ciudad el comercio y los servicios sumaban 94.4\%, en Guacamayas 92.4; en La Mira 95.9; en La Orilla 87.2 y en Buenos Aires, 93.2\%. A excepción de La Orilla, localidad que tradicionalmente juega como área de servicios, en todas predomina la actividad comercial. 
En términos de población económicamente activa (PEA), en el censo de 1990 el sector secundario casi compartía la capacidad de absorción de asalariados que el terciario, lo que subrayó la importancia económica de estas actividades sobre la agropecuaria en el municipio. Para el censo de 2000 predomina la actividad terciaria $(56.4 \%$ de la PEA) sobre el sector secundario $(31.6 \%)$ y decrece en el primario a 6.5 por ciento.

Es en las localidades urbanas, en particular las asentadas en la planicie y con una fuerte incidencia de la actividad portuaria e industrial, donde se multiplica la economía del sector terciario; a tal grado que el comercio y los servicios generan 66 y 68\% de los empleos censados en 1999 y 2004; mientras que en 1989 los establecimientos manufactureros absorbían 65\% de la fuerza de trabajo local.

En particular la actividad en el sector servicios y comercial crece como una opción económica en la localidad, que se extiende luego de la bonanza del flujo financiero derramado por el gasto público y ante la fluctuante crisis económica; y a través de la competencia, subordinación y transformación de las prácticas rurales ante los hábitos urbanos.

\subsection{Las empresas del entorno portuario}

En el entorno inmediato al recinto portuario e industrial, el área donde se localizan diversos servicios de apoyo a empleados y proveedores de las grandes empresas, principalmente transportistas, gasolineras, servicios bancarios, hospedaje, alimentación, recreación nocturna, talleres mecánicos, de servicio y de reparación, estacionamientos de pernocta de tractocamiones o cajas, etc., los negocios establecidos muy poco se enlazan con las grandes empresas.

El centro urbano de Ciudad Lázaro Cárdenas cuenta con servicio telefónico por marcación automática, con telefonía celular y telefonía rural, dispone de un aeropuerto y un aeródromo, 18 oficinas postales, cinco de telégrafos, 16 empresas que prestan el servicio federal de carga y cinco que brindan el servicio federal de pasajeros, 13 oficinas de banca comercial con un plantel de poco más de un centenar de empleados.

En el bloque adyacente de calles que circundan el puerto, los negocios establecidos no tienen encadenamiento directo con las grandes empresas. La mayoría prestan servicios a los operadores de carga y transporte, a la vez que atienden el consumo individual de los trabajadores.

A medida que se reduce la proximidad con respecto al perímetro industrial, en el área propiamente urbana, los negocios se desligan en mayor medida de las actividades manufactureras y se vinculan al comercio y los servicios para el consumo general de la población. 
En general se trata de negocios que podrían clasificarse como micro y pequeñas empresas, con una fuerte carga de informalidad y de gestión familiar, establecidos en la periferia del recinto portuario e industrial, vinculados a los servicios de carga y transporte de materiales e insumos, y buena porción de talleres para el servicio a tractocamiones, servicios de vulcanizadora, refaccionaria, talleres de torno y soldadura, etc. Otro tipo de negocios son para el consumo y reproducción de los trabajadores del área, así como de servicios de transporte colectivo, alimentación, diversión y hospedaje, pequeñas tiendas de abarrotes, vinaterías, panaderías, farmacias, etcétera.

En términos porcentuales, las actividades de comercio y servicios representan 45.6 y 38\%, respectivamente, de la economía del área, en conjunto representan $83.6 \%$. Los establecimientos dedicados a la manufactura representan 16.5 por ciento.

Las unidades económicas orientadas a atender los requerimientos de transporte, en particular de carga pesada y de servicio urbano, representan $36.7 \%$. Aunque no es la actividad dominante, son microempresas de servicio y suministro mecánico a las unidades de transporte. En el negocio del transporte de carga, aun cuando está directamente ligado a las grandes empresas, sus establecimientos no pertenecen al municipio.

A diferencia de los negocios de servicio al transporte, las demás unidades económicas, a medida que se alejan de la zona industrial y portuaria, están más orientadas a satisfacer el consumo general de la población, destacan las tiendas de abarrotes, alimentos, vinos y licores, diversión, recreación nocturna y enseres domésticos, ropa, etc., que se conglomeran con negocios informales establecidos al pie de las calles principales de la localidad.

Asimismo, se registraron escasas industrias manufactureras, microempresas que generan mínimo valor agregado, que además carecen de relación con las industrias instaladas en el puerto. Se trata de algunos talleres de torno, herrerías y otros, son también micronegocios que emplean mano de obra familiar y escasamente calificada.

Por el tipo de actividades comerciales, entre las empresas adyacentes a la zona industrial, $50 \%$ de los establecimientos se dedica a la venta de refacciones y accesorios automotrices; las tiendas de abarrotes representan $36.1 \%$ para atender la demanda de víveres del vecindario. Entre los negocios de servicios predominan los víveres, alimentos, hospedaje y licores, el servicio de automotores y la diversión nocturna, con un total de 70.1 por ciento.

Entre los talleres de manufactura, $46.2 \%$ ofrece servicios de mantenimiento a automotores, $15.4 \%$ se dedica al montaje de hechuras de alu- 
minio y vidrio y $15.4 \%$ a la carpintería. Las tres actividades en conjunto representan un total de $77 \%$ de los negocios manufactureros.

En términos del mercado destino, casi la totalidad de los establecimientos, $93.7 \%$, vende sus productos en el mercado local. Son muy pocos los que podrían atender, incluso, el mercado nacional e internacional. El origen de los insumos (para la comercialización y servicio) son, en 83\%, de procedencia local y nacional, muy pocos son de origen internacional.

Las empresas se caracterizan por su perfil familiar. La mayoría de las unidades económicas son micronegocios, $78.5 \%$ se ubica en el rango de uno a cinco empleados; $2.5 \%$ ocupa entre seis y 10 personas; y $1.3 \%$ a más de 10 trabajadores. Asimismo, 87\% de los empleados son manuales y sólo $13 \%$ son profesionales.

En consecuencia, de los negocios instalados en el entorno inmediato a la zona portuaria e industrial, $55.7 \%$ no tienen, en absoluto, vínculos con las empresas del interior del puerto, operan en atención del consumo de la población (alimentos, abarrotes y diversión); 31.6\% se ocupa en el servicio de la industria del transporte; de $12.7 \%$, aun cuando no tienen relación directa, las empresas del puerto podrían hacer uso de ellas eventualmente (mensajería, paquetería, hospedaje, asesoría legal, vidrios y aluminio, carpintería, etc.), son actividades de servicios que las grandes empresas podrían subcontratar en áreas ajenas a los procesos productivos y administrativos principales.

\subsection{El área rural}

Por otra parte, las localidades agrícolas - conectadas por el pequeño distrito de riego- y la producción comercial frutícola -principalmente de coco-, influenciadas por la expansión urbana, también se han visto obligadas a vincularse al mercado extralocal.

En la medida en que el comercio de medios de subsistencia se abastece con la producción de zonas agrícolas externas (localizadas en Michoacán y en el centro y occidente del país), los productores locales, pecuarios y de frutales se ven inmersos en una trama de canales de transmisión de acaparadores, transportistas y comerciantes, que se apropian del producto y transfieren el excedente generado al exterior de la zona.

En estos términos, en la lógica del mercado local no es posible el control de las redes mercantiles entre los productores agropecuarios, que desconocen los circuitos comerciales, carecen de capital para la circulación de mercancías y están permanentemente requeridos de recursos inmediatos para la inversión y reproducción.

Como consecuencia, en el medio rural persiste un ambiente de estancamiento e incertidumbre, que coincidió con la caída de la producción 
platanera a fines de los ochenta, la conversión y posterior disminución de la producción de mango entre los años noventa y el primer lustro del milenio; a ello se suma la ausencia de un mercado local diversificado y el hecho de que el cultivo de mango no logró constituirse como una opción económica que permitiera superar la restringida subsistencia familiar.

Frente a estas condiciones dadas por la economía en la zona, alternativamente los productores rurales reconstituyen sus prácticas de reproducción a través de la diversificación de sus actividades. Además de la posibilidad del trabajo asalariado industrial, agrícola o de servicios, incorporan en la parcela la producción pecuaria (que dispone de una mayor cabida en el mercado local) y combina los cultivos frutícolas, sobre todo de coco, con productos agrícolas de autoconsumo, como maíz y algunas hortalizas. En esa medida el mercado extralocal y la capacidad de autosubsistencia determinan el manejo y la gestión productiva de los recursos.

En contraste, la ausencia de un mercado abastecido desde adentro limita la capacidad y expectativas de la gestión productiva local. En esa misma medida, la economía de la zona se integra con mínimos impulsos para la organización empresarial y, además, es ajena al comportamiento de los grandes capitales industriales.

\section{Conclusión}

En términos generales, como se puede observar a través de las evidencias recogidas en la zona de estudio, no se advierte una integración industrial mediante importantes enlaces productivos locales, tampoco se cuenta con la capacidad para provocar un desarrollo interno.

Por el contrario, se recrea la situación de un enclave con fuertes dependencias y determinaciones extralocales. Los distintos fragmentos de la economía local y las formas desarticuladas de organización poblacional se determinan en función de circunstancias exógenas. Los factores catalizadores se ubican fuera de la zona, entre los centros de decisión nacional o mundial, cuyos principales agentes -en el contexto de la internacionalización- son las transnacionales y el Estado.

Sólo el flujo de la fuerza de trabajo asalariada se constituye en el único nexo entre las grandes empresas fincadas al interior del recinto portuario con su entorno local. Las numerosas empresas, micro y pequeńas, diseminadas en la amplia zona de la ciudad se alimentan del consumo comercial y de servicios del conjunto de los asalariados que operan en la actividad de las grandes empresas.

Ante la presencia que asume la gran empresa, destaca el carácter accesorio y secundario de los pequeños negocios, desligados unos de otros, como efecto de una economía local estructurada con base en la lógica del 
mercado internacional. Se trata de la separación de espacios contiguos, que albergan condiciones y expectativas diferentes de desarrollo.

Frente a la restringida difusión económica que se genera en la zona, se reconstituyen condiciones de fragmentación poblacional. En primer lugar, ante las diferencias naturales y físicas de la superficie, la influencia económica del complejo industrial alcanza sobre todo a las localidades de la planicie, en función de la proximidad a los principales factores de incidencia (el complejo industrial, la mina, el distrito de riego y los ejes carreteros); mientras que los habitantes del área serrana se reproducen al margen de los estímulos de la actividad económica de la ciudad y de acuerdo con la situación del terreno montañoso que se extiende por la mayor parte del municipio.

Entre esos dos ámbitos naturales, tanto en la planicie como en la sierra, se regeneran condiciones de diferenciación y exclusión socioeconómica, frente a los desiguales efectos de la difusión urbana e industrial y ante las distintas condiciones naturales. El territorio se muestra fragmentado también en función de las características de las localidades, con base en la clasificación de urbanas, rurales y en transición de lo rural a lo urbano. Se denotan las diferencias de acuerdo con el tamańo y proporción de la población, el ritmo de su crecimiento y la principal actividad económica en que se ocupa.

La organización de las localidades es jerarquizada y subordinada ante los estímulos de la actividad industrial, el modo de vida urbano y la disponibilidad de recursos productivos. Son mínimos los niveles de intercambio y la complementariedad entre ellas; por el contrario, se desenvuelven desigualmente como áreas separadas y fragmentadas.

Los impulsos internos de la actividad industrial siguen reducidos a la demanda de mano de obra, inclusive ha disminuido frente a la modernización de los procesos y de las formas de gestión empresarial, ante las dificultades económicas del sector y por el menor e irregular flujo de recursos para la construcción de infraestructura.

Ante un complejo industrial con cabida para la instalación de nuevas empresas que, se aspira en la política regional, compensen la acción centralizadora de la actividad metal-mecánica, la pequeña red local de empresas subcontratistas directamente las controlan y determinan verticalmente las principales empresas. El subcontratismo tiene rasgos informales, se destina en especial a actividades de servicios y construcción y tiene una escasa capacidad de influencia en la economía. Reflejo de esta situación ha sido la quiebra de numerosos subcontratistas frente a las cíclicas crisis de las plantas siderúrgicas en los últimos años.

En contrapartida, frente al aumento de la población, la actividad comercial y de servicios crece en la economía local. A través de numero- 
sas unidades pequeñas y dispersas, el sector terciario tiende a absorber un mayor volumen del empleo.

Por otra parte, aun cuando son pocas las entidades industriales, su dominio en la zona no deja de ser definitivo, por su tamaño y la cantidad de trabajadores ocupados, que aún es significativa, además por la derrama de dinero que se gasta a través de los salarios y para el funcionamiento de la zona.

A pesar del relativo incremento de actividades del sector terciario y la significativa importancia de las industrias, el mercado está fragmentado y responde a impulsos extralocales. La economía se divide en dos grandes circuitos económicos y cada uno se articula a mercados externos separados y diferenciados.

No se trata de condiciones socioeconómicas yuxtapuestas que se rigen con base en principios diferentes; tampoco de economías duales que operan paralelamente con lógicas distintas. Más bien, se refiere a espacios productivos que de modo diferenciado responden a la lógica del capital en condiciones de internacionalización e instituidos de modo singular como resultado de la escasa vinculación entre ellos y como efecto del enclave.

No existe, en consecuencia, una articulación interna entre las diferentes actividades económicas y tampoco se retroalimentan por medio del mercado local.

En un sentido positivo, entre las alternativas que podrían orientar a superar la situación del enclave en la zona han de buscarse en la idea del desarrollo endógeno y en función de las diferentes condiciones de vida de los pobladores que ocupan la región.

Principalmente implicaría una política regional, que no existe, para incorporar las necesidades y las condiciones de reproducción de la amplia extensión agropecuaria: en la planicie y, más aún, en el área serrana que ocupa una gran superficie con escasa capacidad de retención poblacional.

Evitar el predominio de las políticas de crecimiento sectorial de tipo urbano, ya sean en la actividad industrial, el comercio y los servicios, como únicas o principales fuentes de vida, a través de la inversión y el empleo. Dejar de ver a la inversión externa (nacional e internacional) como elemento principal de las políticas de desarrollo.

La inversión sectorial y de atracción externa supone que el desarrollo está en función de extender el régimen del trabajo asalariado como condición de vida de los individuos; aunque sea relegada y marginada la posibilidad de vida familiar y comunitaria de un amplio margen de la población rural.

Por supuesto que la acción de las instituciones (organizaciones fincadas desde el Estado y las agrupaciones sociales) como intermediarias entre la participación social y las formas del poder, ha de involucrarse en 
el encuentro de nuevas formas de gestión pública del desarrollo regional y local.

La descentralización en la toma de decisiones y en la disposición de los recursos por parte de los gobiernos locales, es también un factor central para promover el desarrollo regional/local. Éstos, entre otros aspectos del desarrollo, están ausentes en las acciones del gobierno estatal y municipal en Lázaro Cárdenas, Michoacán.

\section{Bibliografía}

APIlac (Administración Portuaria Integral Lázaro Cárdenas) (2006), Programa Maestro de Desarrollo Portuario 2006-2011, Puerto Lázaro Cárdenas, México.

Barkin, David y Timothy King (1970), Desarrollo económico regional (enfoque por cuencas hidrológicas de México), Siglo XXI, México.

Comisión del Río Balsas-Secretaría de Recursos Hidráulicos (1965), La Villita. Las Truchas. Industrialización de la costa del Pacifico, SRH, México.

Godau, Rainer (1982), Estado y acero. Historia politica de Las Truchas, El Colegio de México, México.

Gobierno del Estado de Michoacán de Ocampo (2008), "Plan Estatal de Desarrollo del Gobierno del Estado de Michoacán, 2008-2012”, Periódico Oficial, 9 de julio, Morelia.

Hermansen, Tormod (1977), "Polos y centros de desarrollo en el desarrollo nacional y regional. Elementos de un marco conceptual", en Antoni Kuklinski (comp.), Polos y centros de crecimiento en la planificación regional, Fondo de Cultura Económica, México, pp. 11-82.

Hiernaux, Daniel (1991), "Del auge a la recesión: ciudad Lázaro Cárdenas, Michoacán. Revisited”, en Gustavo López (coord.), Urbanización y desarrollo en Michoacán, El Colegio de Michoacán-Gobierno del Estado de Michoacán, Zamora, pp. 143-155.

Kerner, Daniel (2003), "La CEPAL, las empresas transnacionales y la búsqueda de una estrategia de desarrollo latinoamericana", Revista 
de la CEPAL, 79, Comisión Económica para América Latina y el Caribe, Santiago de Chile, pp. 85-99.

Martínez Aparicio, Jorge (2006), "El enclave internacional y las desigualdades socioterritoriales", en Jorge Martínez Aparicio y Salvador Padilla Hernández (coords.), Desarrollo local, sustentabilidad y desigualdad en Michoacán, Universidad Michoacana de San Nicolás de Hidalgo, Morelia, pp. 97-119.

Martínez Aparicio, Jorge (1992a), "Sicartsa: de la reconversión a la modernización, 1986-1990”, El Cotidiano, 45, Universidad Autónoma Metropolitana, Azcapotzalco, México, pp. 46-50.

Martínez Aparicio, Jorge (1992b), "De la reconversión a la modernización en las relaciones laborales, 1986-1991", El Cotidiano, 46, Universidad Autónoma Metropolitana, Azcapotzalco, México, pp. 34-53.

Minello, Nelson (1982), Siderúrgica Lázaro Cárdenas Las Truchas. Historia de una empresa, El Colegio de México, México.

Poder Ejecutivo del Estado de Michoacán (1992), Plan de Desarrollo de la Costa Michoacana, 1992-1994, Gobierno del Estado de Michoacán, Morelia.

Poder Ejecutivo del Estado de Michoacán (1998), Programa de Desarrollo Integral de Lázaro Cárdenas, Mich., 1998-2000, Gobierno del Estado de Michoacán, Morelia.

Vázquez Barquero, Antonio (1997), "Gran empresa y desarrollo endógeno. La convergencia estratégica de las empresas y territorios ante el desafío de la competencia", EURE, 23 (70), Pontificia Universidad Católica de Chile, Santiago de Chile, pp. 5-18.

Recibido: 5 de noviembre de 2009. Reenviado: 10 de septiembre de 2010. Aceptado: 18 de marzo de 2011.

Jorge Martínez-Aparicio. Es doctor en ciencias sociales por la Universidad Autónoma Metropolitana, Unidad Xochimilco. Obtuvo la maestría en ciencias en desarrollo rural regional en la Universidad Autónoma 
Chapingo. Es sociólogo por la Facultad de Ciencias Políticas y Sociales de la Universidad Nacional Autónoma de México. Actualmente es profesor-investigador en la Facultad de Economía de la Universidad Michoacana de San Nicolás de Hidalgo; como docente participa en la maestría en ciencias en desarrollo local. Desde 1990 adoptó como un laboratorio de investigación al municipio Lázaro Cárdenas, Michoacán. Ha producido diversas publicaciones y ponencias sobre desarrollo socioeconómico y cambios socioterritoriales, desde diferentes enfoques que tienen que ver con los cambios en las condiciones de apropiación de los soportes materiales, las relaciones laborales y la actividad siderúrgica, correspondencia entre el campo y la ciudad, cambios en la composición poblacional, transformaciones regionales y en el ámbito internacional. Actualmente aborda como líneas de investigación el desarrollo local, la economía social y el territorio. 